Original Research Paper

\title{
Pelatihan Pembuatan Pupuk Organik dengan Bioteknologi EM4 (Effekctive Microorganism) untuk Pengolahan Limbah Ternak di Kelompok Pemuda Mandiri Bug-Bug Lingsar Lombok Barat
}

\author{
Mohammad Liwa Ilhamdi $^{1 *}$, Agil Al Idrus ${ }^{1}$, Lalu Muhyi Abidin², Lale Yaquttunafis², Baiq Salkiyah² \\ 1. Pendidikan Biologi Universitas Mataram \\ ${ }^{2}$ Universitas Nahdlatul Wathon Mataram
}

https://doi.org/10.29303/jpmpi.v3i2.981

Sitasi: Pribadi, M. L., Idrus, A. A., Abidin, L. M., Sakiyah, B., Maryani, Y., Yaquttunafis, L \& Salkiyah, B (2021). Pelatihan Pembuatan Pupuk Organik dengan Bioteknologi Em4 (Effekctive Microorganism) untuk Pengolahan Limbah Ternak di Kelompok Pemuda Mandiri Bug-Bug Lingsar Lombok Barat. Jurnal Pengabdian Magister Pendidikan IPA, 4(3)

\section{Article history}

Received: 1 September 2021

Revised: 25 September 2021

Accepted: 27 September 2021

*Corresponding Author:

Mohammad Liwa Ilhamdi,

Universitas Mataram,

Mataram, Indonesia

Email:

liwa_ilhamdi@unram.ac.id

\begin{abstract}
Beternak merupakan salah satu aktivitas kelompok pemuda mandiri (PKM) Bug-Bug Lingsar Lombok Barat. Aktivitas ini menghasilkan limbah ternak yang dapat mengotori lingkungan jika tidak dikelola dengan baik. Limbah dapat berupa kotoran padat, cair maupun bekas sisa-sisa makanan ternak. Salah satu upaya pemanfaatan limbah ini adalah menjadikannya pupuk organic dengan bioteknologi EM4. Permasalahan yang dihadapi oleh Kelompok Pemuda Mandiri Bug-Bug Lingsar Lombok Barat adalah belum mengetahui cara mengolah limbah ternaknya menjadi pupuk organik. Tujuan kegiatan adalah untuk melatih anggota KPM membuat pupuk organic dari limbah ternak dengan bioteknologi EM. Metode pelaksanaan kegiatan pengabdian masyarakat ini adalah pelatihan, praktek dan pendampingan masyarakat mitra pengabdian. Hasil pengabdian menunjukkan bahwa pelatihan pembuatan pupuk organik dengan bioteknologi EM4 (Effekctive Microorganism) untuk pengolahan limbah ternak dapat meningkatkan pengetahuan dan keterampilan anggota KPM dan pembuatan pupuk organik sudah dapat dilakukan dengan baik oleh KPM serta implementasi penggunaan teknologi EM-4 di KPM dapat $100 \%$ mengatasi limbah ternak untuk dijadikan pupuk organik.
\end{abstract}

Kata Kunci: Pupuk Organik, Limbah ternak, EM4

\section{Pendahuluan}

Umumnya tujuan beternak adalah untuk mendapatkan daging melalui proses pertambahan berat badan. Selain menghasilkan daging, dalam beternak juga dihasilkan produk lain berupa limbah ternak seperti urin, kotoran ternak dan sisa makanan ternak. Limbah adalah bahan sisa atau buangan yang dihasilkan dari suatu kegiatan dan proses produksi, baik pada skala rumah tangga, industri, pertambangan, dan sebagainya. Bentuk limbah tersebut dapat berupa gas dan debu, cair atau padat (Husain, et al. 2014). Sisa berbagai produk beternak tersebut, mendatangkan masalah yang bisa merepotkan pemilik ternak. Bahan ini tentu tidak bisa dibiarkan begitu saja, karena selain mengganggu dan mengotori lingkungan, juga 
sangat berpotensi untuk menimbulkan penyakit bagi masyarakat sekitarnya. Oleh karena itu perlu upaya untuk mengatasinya, salah satunya dengan menjadikan limbah ternak tersebut menjadi pupuk organik.

Pengelolaan limbah terutama di kandangkandang ternak belum banyak dilakukan masyarakat karena kurangnya pengetahuan dan pengalaman menjadikan lingkungan sekitar peternakan menjadi kurang sehat terutama dari sisi estetika, bau dan sumber penyakit. Limbah ternak merupakan bahan buangan dari ternak dan menurut masyarakat bahan tersebut tidak berguna dan perlu dibuang. Namun jika limbah ternak ini dimanfaatkan dengan baik maka dapat mendatangkan keuntungan bagi peternak dan petani karena dapat dimanfaatkan menjadi pupuk organic sehingga masyarakat tani tidak perlu lagi membeli pupuk yang harganya sekarang sudah mahal.

Penggunaan pupuk organic sekarang mulai dikembangkan karena Parnata (2004) menyatakan penggunaan pupuk anorganik di Indonesia mampu meningkatkan hasil pertanian, namun tanpa disadari penggunaan pupuk anorganik secara terus menerus berdampak tidak baik bagi sifat fisik, kimia dan biologi tanah. Hal itu menyebabkan kemampuan tanah untuk mendukung ketersediaan air, hara dan kehidupan mikroorganisme dalam tanah menurun. Kondisi ini terjadi karena tingkat kesuburan dan bahan organik tanah mengalami penurunan, oleh karena itu jika tidak segera diatasi maka dalam jangka waktu tidak terlalu lama, lahan-lahan tersebut tidak mampu lagi berproduksi secara optimal dan berkelanjutan.
Salah satu daerah di Lombok Barat yang warganya masih memelihara ternak kuda, kambing, sapi, ayam dan lain-lain adalah wilayah Bug-Bug Lingsar.

Tujuan dari kegiatan pengabdian ini ialah: (1) Mengimplementasikan bioteknologi EM4 pada kelompok masyarakat mitra untuk mengelola limbah ternak menjadi pupuk organik (2) Transfer bioteknologi perbanyakan kultur EM. Tujuan tersebut dicapai dalam waktu 6 bulan dengan melakukan transfer teknologi meliputi pelatihan pengelolaan limbah ternak dengan menjadikannya sebagai bahan baku pembuatan pupuk organic dengan bioteknologi EM4, pelatihan perbanyakan kultur EM4.

Adapun permasalalahan yang dihadapi oleh masyarakat peternak dan petani adalah (1) Pengetahuan masyarakat peternak tentang pengelolaan limbah ternak masih sangat rendah terutama dengan penggunaan bioteknologi EM4. (2) Cara pembuatan pupuk organic dari limbah ternak belum diketahui dengan baik.

Upaya-Upaya yang dilakukan melalui pengelolaan limbah ternak, pembuatan pupuk dengan bioteknologi EM4 diharapkan mampu mendatangkan keuntungan peternak dan masyarakat sekitar dengan menghasilkan pupuk organik yang baik.

\section{Metode Pelaksanaan}

Metode pelaksanaan kegiatan pengabdian masyarakat tentang pengelolaan limbah ternak dengan bioteknologi EM4 menjadi pupuk organic di Bug-Bug adalah :
1. Survey 
Melakukan survey data lapangan untuk memperoleh data kondisi peternakan masyarakat

2. Sosialisasi, Pelatihan dan Praktek

Metode sosialisasi dan pelatihan tentang pembuatan pupuk organik dari limbah ternak dengan bioteknologi EM 4 dan cara memperbanyak EM4. Kegiatan pelatihan disampaikan secara klasikal, semua peserta mengikuti materi melalui ceramah, diskusi, dan Tanya jawab.

Setelah kegiatan pelatihan dilakukan, dilanjutkan dengan kegiatan praktek pembuatan pupuk organik. Praktek pembuatan pupuk organik dilakukan oleh semua anggota KPM (Kelompok Pemuda Mandiri) Bug-Bug .

3. Pendampingan

Pasca kegiatan pelatihan dan praktek, dilakukan pendampingan bersama mitra untuk memastikan bahwa pembuatan pupuk organik yang dilakukan oleh peserta pelatihan dapat berhasil dengan baik sesuai dengan yang diharapkan.

\section{Hasil dan Pembahasan}

\section{A. Survey}

Hasil survey yang dilakukan menunjukkan bahwa peternak belum pernah mengolah limbah ternaknya menjadi pupuk organic yang dapat dimanfaatkan lagi untuk bertani. Namun mereka mempunyai kemauan yang kuat untuk memanfaatkan limbah ternaknya menjadi pupuk tetapi mereka belum mengetahui cara membuat pupuk organic dari limbah ternak.

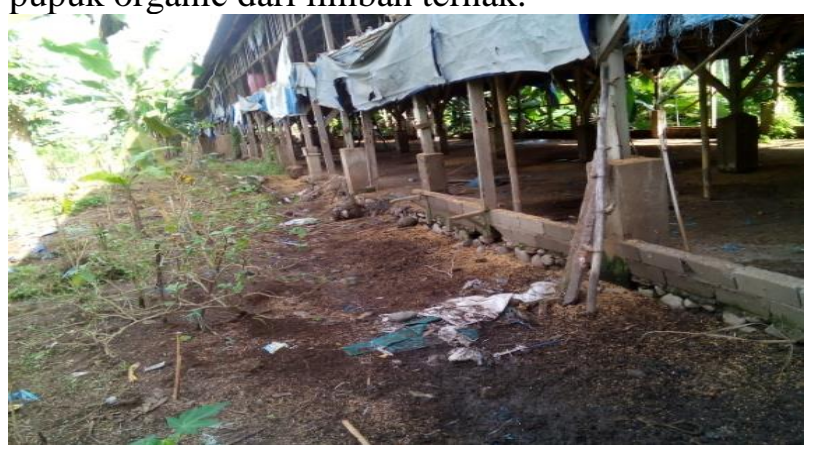

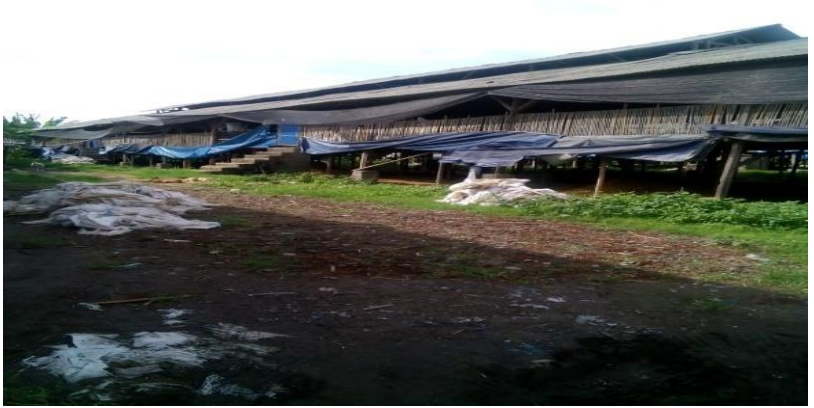

Gb.1. Kondisi kandang peternakan

\section{B. Sosialisasi, Pelatihan dan Praktek Pengelolaan Limbah Ternak}

Sosialisasi dilakukan dengan penyuluhan pada kelompok peternak yang dihadiri oleh kelompok pemuda mandiri berjumlah 18 orang yang berasal dari wilayah Bug-Bug dan sekitarnya. Pada kegiatan ini dilakukan penyuluhan materi kegiatan yaitu tentang pentingnya pengelolaan limbah ternak agar lingkungan menjadi bersih dan dapat bermanfaat bagi peternak sendiri maupun bagi petani dengan menyemprotkan EM 4 pada kandang ternak agar kandang tidak berbau dan selanjutnya setelah limbah ternak mulai banyak dikumpulkan dan diproses dengan bantuan EM4 menjadi pupuk organic. Selanjutnya disampaikan Teknis pembuatan pupuk organic dari limbah ternak, perbanyakan kultur EM4.

Dalam pemaparan disampaikan bahwa pentingnya mengelola limbah ternak bagi kesehatan dan keuntungan para peternak untuk Kesehatan ternak, peternak dan lingkungan sekitar.

Pemaparan selanjutnya disampaikan bahwa untuk membuat pupuk organic dari limbah ternak sangat mudah dengan campuran EM4 limbah ternak dapat menjadi pupuk organic yang siap dimanfaatkan untuk tanaman pertanian maupun perkebunan.

Setelah sosialisasi dilakukan pelatihan dan praktek pengolahan limbah ternak dengan melatih para peserta membuat pupuk organic dari limbah ternak dengan menerapkan teknologi EM4 dan perbanyakan kultur EM4.

\section{a. Pembuatan pupuk organic dengan EM4}

Langkah pertama adalah menyediakan bahan sebagai berikut : limbah ternak yang sudah dikumpulkan dari kandang ternak, Dedak $10 \mathrm{~kg}$, Sekam $200 \mathrm{~kg}$, Gula (10 sendok makan), $\mathrm{EM}_{4} 200 \mathrm{ml}$ (20 sendok makan), air secukupnya. Cara pembuatannya Larutkan EM4 dan gula ke 
dalam air, kemudian Pupuk kandang, sekam dan dedak dicampur secara merata. Siramkan larutan EM4 secara perlahan-lahan ke dalam adonan secara merata sampai kandungan air adonan mencapai 30\%. Bila adonan doikepal dengan tangan air tidak keluar dari adonan dan bila kepalan dilepas, maka adonan akan merekah. Adonan digundukkan di atas tempat yang kering dengan ketinggian tumpukan $15 \mathrm{~s} / \mathrm{d} 20 \mathrm{~cm}$, kemudian ditutup dengan karung goni selama 3 s/d 4 hari. Pertahankan suhu gundukan adonan $40 \mathrm{~s} / \mathrm{d} 50^{\circ} \mathrm{C}$. Jika suhu lebih dari $50^{\circ} \mathrm{C}$, bukalah karung penutup dan gundukan adonan dibolakbalik kemudian ditutup lagi dengan karung goni. Suhu yang tinggi dapat mengakibatkan calon pupuk organik menjadi rusak karena terjadi proses pembusukan. Pengecekan suhu dilakukan setiap 5 jam. Setelah 4 hari Bokashi telah selesai terfermentasi dan siap digunakan sebagai pupuk orgaik.

\section{b. Perbanyakan kultur EM4}

Untuk menghemat biaya, bibit bakteri EM4 yang dibeli di toko atau koperasi Saprotan dapat dikembangbiakkan sendiri, sehingga kebutuhan pupuk organik untuk luas lahan yang ada dapat dipenuhi. Bahan dan Komposisi alat bahan yang diperlukan sebagai berikut 1 liter bakteri (EM4), 1,5 kg bekatul (minimal), 1/4 kg gula merah/gula pasir/tetes tebu (pilih salah satu), $1 / 4 \mathrm{~kg}$ terasi, 1 liter air. Adapun Cara pembuatannya : Panaskan 5 liter air sampai mendidih Masukkan terasi, bekatul dan tetes tebu/gula (jika memakai gula merah harus dihancurkan dulu), lalu aduk hingga rata.Setelah campuran rata, dinginkan sampai betul-betul dingin! (karena kalau tidak betul-betul dingin, adonan justru dapat membunuh bakteri yang akan dibiakkan). Masukkan bakteri dan aduk sampai rata. Kemudian ditutup rapat selama 2 hari. Pada hari ketiga dan selanjutnya tutup jangan terlalu rapat dan diaduk setiap hari kurang lebih 10 menit. Setelah 3-4 hari bakteri sudah dapat diambil dengan disaring, kemudian disimpan dalam botol yang terbuka atau ditutup jangan terlalu rapat (agar bakteri tetap mendapatkan oksigend ari udara). Selanjutnya, botol-botol bakteri tersebut siap digunakan untuk membuat kompos, pupuk cair maupun pupuk hijau. Sebagai catatan: Ampas hasil saringan dapat untuk membiakkan lagi dengan menyiapkan air kurang lebih 1 liter dan menambahkan air matang dingin dan gula saja.
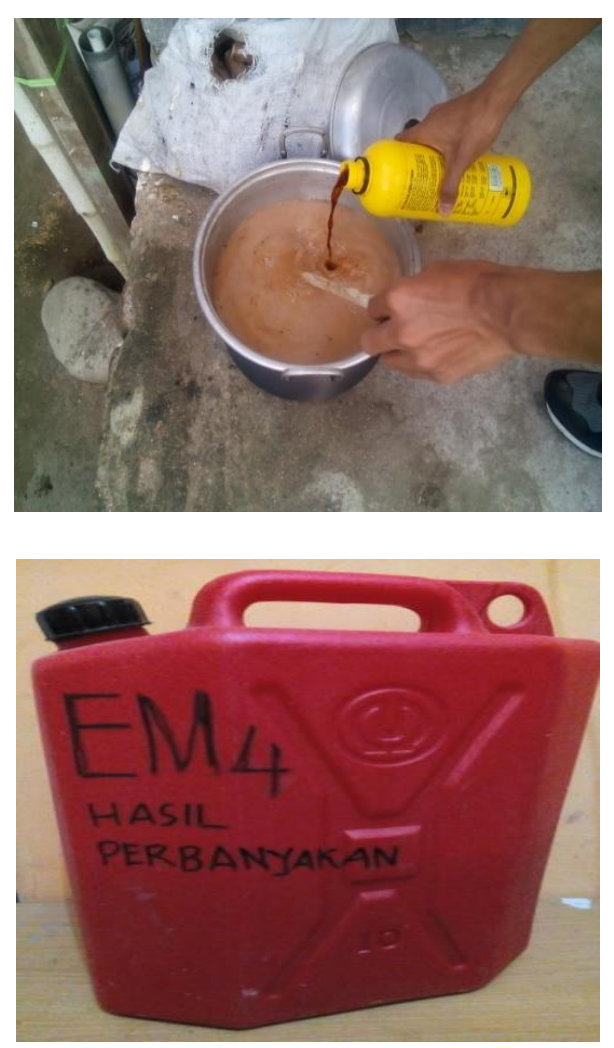

Gambar 2: Pelatihan Perbanyakan EM4

\section{c. Pendampingan}

Pendampingan dilakukan untuk memastikan pelaksanaan kegiatan pembuatan pupuk organik dari limbah ternak dengan EM4 dilakukan dengan benar dan tepat. Pendampingan juga berguna untuk sarana bagi anggota KPM Bug-Bug bertanya langsung cara yang tepat dan benar dalam pembuatan pupuk organik dari EM4.

\section{Kesimpulan}

Kesimpulan dari kegiatan ini adalah :

1. Semua peserta kegiatan pengabdian pengelolaan limbah ternak dengan menggunakan bioteknologi EM4 sangat antusias mengikuti seluruh rangkaian kegiatan.

2. Pengelolaan limbah ternak sudah dilakukan dengan baik dan 100\% menjadikannya pupuk organic. 
3. Perbanyakan EM4 dilakukan dengan benar dengan menghasilkan EM4 hasil perbanyakan yang berkualitas.

\section{Ucapan Terimakasih}

Ucapan terima kasih kepada Rektor Universitas Nahdlatul Wathon yang telah memberikan dana dalam kegiatan ini.

\section{Daftar Pustaka}

Anonim, 2021,

http://diperta.ntbprov.go.id/data base/pup uk_organik.htm, diambil pada tanggal 1 April 2021, pukul 09.00

Anonim, 2021,

http://www.suarantb.com/2010/07/22/Sosi al/detil5\%201.html, diambil pada tanggal 5 April 2021 pukul 11.001

Anonim, 2021, http : komoditas sentra. Kabupaten

Lombok Barat. diambil pada tanggal 10

April 2021, pukul 10.00

HigaTeruo, 1998, Materi Latihan Teknologi EM, Departemen Pertanian, Jakarta.

Husain, D. Sukarsono, N. Mahmudati. 2014. Pengaruh Jumlah Cacing Tanah (Lumbricus rubellus) dan Waktu Pengomposan Terhadap Kandungan NPK Limbah Media Tanam Jamur Tiram sebagai Bahan Ajar Biologi. Jurnal pendidikan biologi indonesia, Vol.1 (1):1-8

Parnata, A. S. 2004. Pupuk Organik Cair Aplikasi dan Manfaatnya. Agromedia Pustaka. Jakarta.

Sardjoko, 1991, Bioteknologi, Gramedia Pustaka Utama, Jakarta. 